ORIGINAL ARTICLE

\title{
Exploring the influence of Internet-based caregiver support on experiences of isolation for older spouse caregivers in rural areas: a qualitative interview study
}

\author{
Madeleine Blusi RN, PhD Nursing Sciences \\ Department of Research \& Development, Association of Local Authorities in Västernorrland County, Härnösand, Sweden and \\ Department of Nursing, Mid-Sweden University, Campus Sundsvall, Sundsvall, Sweden
}

Lisbeth Kristiansen RN, PhD, Ass.professor in Nursing Sciences

Department of Nursing, Mid-Sweden University, Campus Sundsvall, Sundsvall, Sweden

Mats Jong RN, PhD, Ass.professor in Nursing Sciences

Department of Nursing, Mid-Sweden University, Campus Sundsvall, Sundsvall, Sweden

Submitted for publication: 2 March 2014

Accepted for publication: 29 September 2014

\section{Correspondence:}

Madeleine Blusi

Kommunförbundet Västernorrland, Järnvägsgatan 2

87145 Härnösand Härnösand

Sweden

E-mail: madeleine.blusi@kfvn.se

Telephone: +46 (0)703551848
BLUSI M., KRISTIANSEN L. \& JONG M. (2015) Exploring the influence of Internet-based caregiver support on experiences of isolation for older spouse caregivers in rural areas: a qualitative interview study. International Journal of Older People Nursing 10, 211-220. doi: 10.1111/opn.12074

Background. Many older spouse caregivers are tied to the home by their caring duties and feel isolated. The values of supporting older caregivers are well known. In rural areas with long distances and decline in essential services, attending caregiver support groups can be difficult. Using Internet-based services can provide an opportunity for rural caregivers to participate in caregiver support, regardless of geographical distances and without the need for physical presence.

Aims and objectives. This study aimed to explore how Internet-based caregiver support may influence the experience of isolation among older spouse caregivers in rural areas.

Design. An intervention study where 63 older rural caregivers received an Internetbased caregiver support service.

Method. A qualitative interview study based on 31 interviews with open-ended questions, analysed using latent content analysis.

Findings. Two themes represent the findings from the study: Expanding the concept of place and Developing networks. Even though participants still spent their days in the house, they experienced that daily life was being spent in a variety of places, both physically, virtually and emotionally. The Internet-based support service provided them with a tool to reconnect with family and develop new friends.

Conclusions. Internet-based caregiver support may reduce the experience of isolation for spouse caregivers in rural areas. Nurses played a crucial part in the development, by encouraging, educating and inspiring caregivers and supporting their independence.

Implications for practice. Internet-based services ought to be an option for caregiver support in rural areas as it may reduce feelings of isolation for older spouse caregivers. 
Key words: caregiver support, internet, isolation, older people, place, rural nursing

\section{What does this research add to existing knowledge in gerontology?}

- Using Internet-based caregiver support can counteract isolation for older spouse caregivers in rural areas.

- Despite entrapment in the house, caregivers using Internet can experience spending daily life in a variety of places both physically, virtually and emotionally.

\section{What are the implications of this new knowledge for nursing care with older people?}

- To challenge traditional values that caregiver support for older spouse caregivers need to be based on physical meetings.

- To inspire nurses to use the Internet and modern technology in communication with, and care of, older people.

\section{How could the findings be used to influence policy or practice or research or education?}

- Providers of caregiver support in rural areas should consider offering Internet-based caregiver support as a mean to make caregiver support more accessible.

- Nurses, the largest category of healthcare workers, can be a resource in inspiring older people in rural areas to use Internet as a tool for support and promoting health.

\section{Introduction}

Older people increasingly live in their own homes for as long as possible, even though care needs may be extensive (Hagberg, 2012). Many of them live together with a spouse who needs help and care in order to manage ever-day life (McConaghy \& Caltabiano, 2005; Larsson, 2006). Family caregivers are taking on a great responsibility, in Europe and the USA; nearly 80 per cent of care hours for older people are provided by family caregivers (Marin et al., 2009; Hoffmann \& Rodrigues, 2010; Alzheimer's Association's, 2011). They also play a strategic role in future provision of long-term care services, which is a challenge for many countries (European Commission, 2008).

The value of family caregivers has been recognised, and many countries have introduced enhanced caregiver support (Kröger, 2003; Winqvist, 2010). In 2009, the Swedish Parliament passed a law stating that municipalities are obliged to offer support to persons caring for people with chronic illnesses, older people or people with functional disabilities, acknowledging the importance to support family caregivers (Swedish Social Services Act, 2009). Different types of support services are available, such as support groups, counselling and monetary support (Lamura et al., 2008).

In rural areas, there is an ongoing change in social infrastructure with depopulation and loss of community services (Phillipson \& Scharf, 2005). There identifies rural areas as municipalities with a population density below 150 inhabitants per square kilometre. National Swedish definitions classify municipalities with less than seven inhabitants per square kilometre as rural. In year 2007, according to the Swedish definitions, $24 \%$ of Sweden's nine million inhabitants lived in rural areas (Swedish National Rural Development Agency, 2007). Due to geographical distances and limited service availability, it can be difficult for spouse caregivers living in rural areas to access caregiver support. Internet-based support services have the potential to make caregiver support in rural areas more available, since it can be provided regardless of geographical distances (Schmidt et al., 2011; Blusi et al., 2013). This feature may be essential in order to meet future rural care needs (Carretero et al., 2012). Internet-based caregiver support enables individually adjusted support to meet individual needs (Blusi et al., 2014). It can also have a positive impact on caregivers' quality in daily life and facilitate social participation (Magnusson et al., 2005; Blusi et al., 2013).

From an international perspective, Sweden has good Internet connections with high accessibility to broadband (Post \& Telecom Authorities, 2010). Adults aged over 65, living in rural areas, are less frequent users of Internet than their equivalents in urban areas. A recent Swedish study investigating Internet use among persons age over 65 showed that $19 \%$ of persons in rural areas use Internet, compared to $30 \%$ in urban areas (Berner et al., 2014). For nurses working with providing caregiver support, utilisation of Internetbased support services entails a change in nurses' role as the different way of providing support raises a need for profes- 
sionals and family caregivers to work in partnerships (Magnusson et al., 2005).

Older caregivers in rural communities are at significant risk of social isolation (Winterton \& Warburton, 2011). Taking on caring responsibilities can result in loss of social networks (Cockram et al., 2007). For older caregivers in rural areas, isolation factors are intensified by relocation of family and limited support services (Winterton \& Warburton, 2011).

The intensity of caring tasks, often with need for constant presence at home, leads to many caregivers experiencing feelings of isolation and loneliness. Even though loneliness is an essential factor which has negative impact on quality of life among older persons, in line with the definition of social isolation as 'a state in which the individual lacks sense of belonging socially, lacks engagement with others, has a minimum of social contacts and they are deficient in fulfilling and quality relationship' (Nicholson, 2012), we view isolation as the overarching that also includes loneliness. Social isolation has both a physical and spiritual dimension where experiences of isolation and lack of social networks have negative effects on caregivers' own health (Ekwall et al., 2004; McConaghy \& Caltabiano, 2005; Hoffmann \& Rodrigues, 2010). Isolation is also a factor found to be highly associated with subjective burden (Leggett et al., 2011). Burden, depression and the presence of an unmet service need are significantly associated with caregivers desire to institutionalise the one they care for (Gallagher et al., 2011).

Taking on the role as caregiver is rarely a choice made deliberately, it usually develops over time (Johansson, 2007). Caring is fundamental to the human way of being and it sets up what matters to a person as well as what counts as stressful. Providing care involves committing to the needs of another person (Benner \& Wrubel, 1989). Spouse caregivers commonly become devoted to their roles, often at the expense of their own needs, including social interaction. Their responsibilities infringe on their personal and social lives (Burton et al., 2004). Many older spouse caregivers are tied to their home by their caring duty. They may not want to, or are afraid of leaving the home and the cared for spouse alone (Sand, 2005; Johansson, 2007). For some, the home becomes almost the only place where they spend their time (Keating, 2008; Hagberg, 2012).

While working on a study with the purpose of exploring older family caregivers' experiences from receiving Internetbased caregiver support, we found that participants spoke extensively about isolation and loneliness, even though there were no particular questions about these topics (Blusi et al., 2013). They told stories about how using the Internet reduced such feelings and also added new dimensions to daily life. Within the aim of the original study (Blusi et al., 2013), it was not possible to further explore details about how using Internet-based support affected loneliness and isolation.

As it appeared to be of importance to the caregivers, the research team decided to use data collected within the original study, but not previously analysed, to get a deeper understanding for how Internet-based support had influenced caregivers' experiences of isolation.

The aim of this study was to explore how Internet-based caregiver support may influence the experience of isolation among older spouse caregivers in rural areas.

\section{Method}

This study is based on data not previously analysed but originally collected for another study, referred to as the original study (Blusi et al., 2013). In this current study, we focused on units of data that had not been previously analysed, in order to obtain a deeper understanding of caregivers' experiences of isolation. For further details regarding the method of the original study, please refer to Blusi et al. (2013).

\section{Participants and recruitment}

In the original study which had a comparative design, the intervention (Internet-based caregiver support) was provided to spouse caregivers living in 15 different local municipalities in northern Sweden. Inclusion criteria were to be caregiver to a cohabiting spouse with chronic illness, aged over 65 years old and still living in their own home in a rural area. Participants had been consecutively invited for participation as they came in contact with support nurses in each municipality and were included in the study after informed consent. Interviews were conducted with 31 participants: eight men and 23 women between 65 and 85 years of age, and mean age was 74 years. Rural area was defined according to two commonly used Swedish definitions: (i) more than 45 minutes ride by car to the nearest densely built-up area/town of more than 3000 inhabitants and (ii) between 5 and 45 minutes ride by car to the nearest densely built-up area/town of more than 3000 inhabitants (Swedish National Rural Development Agency, 2007).

\section{Setting and intervention}

The study was performed in sparsely populated areas (4, 5 persons $/ \mathrm{km}^{2}$ ) in mid- and northern Sweden. Participants were 
provided with the ACTION service (Magnusson et al., 2005) which included computer, web camera and ADSL-Internet access in their homes. Information and educational software focusing on areas encountered in daily caring were also included, along with a secure social community where they were encouraged to make video calls and interact with support nurses and peer caregivers. The core of the intervention was that participants were educated by support nurses regarding how to use the Internet-based caregiver support service. Nurses also actively encouraged participants to use the service on their own.

\section{Data collection}

Interviews were conducted after 18 months of using the Internet-based caregiver support service. The participants took part in the intervention study for 3 years. The first participants enrolled in 2008 and the last one joined in 2010. Data for this study were collected after one and a half year of using the intervention for each participant, during 20092011. Interview data were collected from all participants prior to start of analysis. During the interviews (Kvale \& Brinkmann, 2009), participants were asked to speak freely about their experiences of using Internet-based caregiver support. Example of open-ended questions asked were 'Please tell me about your experiences from receiving internet based support', 'How has the support affected your daily life' and 'What kind of problems have you encountered while using the support?'. When needed, follow-up questions were added. The interviews, lasted between 50 and 60 minutes, were audio recorded and transcribed verbatim. The total data material consisted of 450 pages of double spaced text. For this study, meaning units containing data related to isolation were sorted out from the text and analysed. This data occurred throughout the interviews and constituted about $25 \%$ of the total text.

\section{Data analysis}

In the original study (Blusi et al., 2013) as well as this present study, data analysis was performed using qualitative content analysis inspired by Graneheim and Lundman (2004) and Patton (2004). The analysis was performed in several steps, starting with reading through every interview several times in order to get a sense of the text as a whole. The text was divided into meaning units, containing one or more sentences which were condensed. The condensed meaning units were read and interpreted to identify the latent meaning representing a higher level of abstraction. In order to analyse the topics addressed in the aim of this substudy, we asked the following questions to the text: 'What do they feel when using the internet based caregiver support?' and 'How do the use of the internet based caregiver support service affect their experience of isolation?' Passages related to the same content were interpreted and formulated as six subthemes, which comprise threads of meaning running through the condensed text. The process of analysis was not linear from starting point to an endpoint, but rather a movement back and forth between the whole and parts of the text, a process of consistent reflection and discussion among the authors, leading to revisions of the themes, giving room for renewed starting points. Finally, the latent content was formulated into two overarching themes. Example of the process of text analysis is shown in Table 1 . The analysing process followed the same pattern for both themes. The use of the abbreviations I1-I9 for quotations in the findings section respond to the consecutive number of interviewees and illustrate that the quotes come from a variety of informants. QSR International's NVivo 9 qualitative data analysis software was used in the process of text analysis (NVivo, 2012).

\section{Ethical considerations}

The study was approved by the Research Ethics Committee of the Medical Faculty at Umea University, Sweden (Dnr 2010-187-31). Participants were guaranteed confidentiality and assured that withdrawal from the study would not exclude them from access to further support. They were guaranteed to keep the technical equipment and have full access to services included in the intervention for the entire project period, at no cost, even if they declined participation in the interview study.

\section{Findings}

Interviews revealed that the participants experienced Internet-based support to be a bridge to a life that felt less isolated. In the analysis, the following two themes were identified: Expanding the concept of place and Developing networks. An overview of the findings is shown in Table 2.

\section{Expanding the concept of place}

This theme constituted of three subthemes; Reconnecting with familiar places, Exploring new places and New meaning to existing rooms in the home. Participants described how the caring responsibilities made it difficult for them to leave the house. The physical place where their lives took place had by passing time become small and restricted. Participating in Internet-based caregiver support broadened their perception 
Table 1 Example of the process of content analysis, with condensed meaning units, subthemes and themes

\begin{tabular}{|c|c|c|c|}
\hline $\begin{array}{l}\text { Condensed meaning unit. } \\
\text { Description close to the text }\end{array}$ & $\begin{array}{l}\text { Condensed meaning unit. } \\
\text { Interpretation of } \\
\text { the underlying meaning }\end{array}$ & Subtheme & Theme \\
\hline $\begin{array}{l}\text { Visiting websites and looking at pictures } \\
\text { from places they lived before }\end{array}$ & $\begin{array}{l}\text { Feels like visiting that } \\
\text { place }\end{array}$ & \multirow[t]{2}{*}{$\begin{array}{l}\text { Reconnecting with familiar } \\
\text { places }\end{array}$} & \multirow[t]{6}{*}{$\begin{array}{l}\text { Expanding the } \\
\text { concept of place }\end{array}$} \\
\hline $\begin{array}{l}\text { Reading newspapers from places where they } \\
\text { used to live }\end{array}$ & $\begin{array}{l}\text { Resuming contact with } \\
\text { place from the past }\end{array}$ & & \\
\hline $\begin{array}{l}\text { Looking at photos from places they dream } \\
\text { of visiting }\end{array}$ & Virtual travelling to new places & \multirow[t]{2}{*}{ Exploring new places } & \\
\hline $\begin{array}{l}\text { Visiting websites and streamed events regarding } \\
\text { a hobby or something they find interesting } \\
\text { (football, crafting etc.) }\end{array}$ & $\begin{array}{l}\text { Discovering the possibility to } \\
\text { participate in virtual places } \\
\text { and activities }\end{array}$ & & \\
\hline $\begin{array}{l}\text { Spouse is jealous and does not want caregiver to } \\
\text { use the computer. Computer is kept it upstairs } \\
\text { where spouse can't see it }\end{array}$ & Using place for finding privacy & \multirow[t]{2}{*}{$\begin{array}{l}\text { New meaning to existing } \\
\text { rooms in the home }\end{array}$} & \\
\hline $\begin{array}{l}\text { Anxious spouse leads to feeling trapped in one } \\
\text { room. Having the computer in that room enables } \\
\text { caregiver 'to do things' even though space is limited }\end{array}$ & Using place to include & & \\
\hline
\end{tabular}

Table 2 Overview of the subthemes and themes

\begin{tabular}{ll}
\hline Subthemes & Themes \\
\hline Reconnecting with familiar places & Expanding the concept of place \\
Exploring new places & \\
New meaning to existing rooms & \\
in the home & \\
Revitalising of social and & Developing networks \\
supportive connections & \\
Reconnecting with the ill person & \\
Developing relationships with & \\
technology and objects & \\
\hline
\end{tabular}

of the home and the space they lived in. Even though the participants stayed in their homes almost all of the time, they expressed different ways of relating to place that during the intervention had become part of their daily living. Despite being unable to leave the home physically, they experienced feelings of spending time in different places.

\section{Reconnecting with familiar places}

Using Internet made participants feel like they were at other places than in the home. Participants talked about reading online newspapers from places where they used to live. Being able to re-establish this emotional connection with the old place gave a sense of satisfaction and still belonging. Being able to pay a virtual visit to other places reduced the boundaries of the home and thus the feeling of isolation.

I1, Woman 83 years: We moved here from another region. I loved it there but will never get the opportunity to go back. Everything changes. On internet I can see pictures of what it looks like these days, and keep up with what is happening there. I was happy there and it makes me feel good to escape there every now and then. Satellite photos allow going on excursions.

\section{Exploring new places}

Place attachment was one perspective brought up by the participants. In using the computer, they did not only visit places they felt attached to from old times. They also allowed themselves to get attached to new places they had never visited in real life. Using the computer to explore the world was a way to 'get out of the house', sometimes together with the spouse. Participants also experienced that it was possible to visit the homes of others.

I2, Woman 83 years: We take trips you see, to tropical places we didn't know about. It is so easy on the internet. We pretend we go there, and I tell her about all the things we do when we are there. We have found nice new places and call them ours.

I3, Woman 72 years: Our son has lived in a different part of the country over 20 years. I have never visited him there. He took his webcamera and walked around in the house and showed me. Now I feel like I have been in his house, and I can be part of their home and be with them.

\section{Existing rooms gaining new meaning}

Place was not only reflected on as being outside of the home or far away. Different places within the home became of more importance and were used both for inclusion and finding privacy. Design and planning of the home played a significant role in how the participants arranged their daily lives. If the cared for spouse had physical limitations, most of 
every-day-life was focused to the parts of the house the spouse had access to. The participants sometimes felt trapped to those parts of the house. On the other hand, participants also felt that other parts of the house had become their own, a place of sanctuary from caring and relief from being tied down.

I4, Woman 78 years: He is very jealous and goes crazy every time I just talk on the phone. He doesn't know about the computer, I keep it upstairs. I have always gone upstairs knitting and he is fine with that.

When the participants enrolled in the study, they had highspeed Internet installed in their houses. Before installing, they had to choose where in the house to put the computer. It was common to choose a place out of the way, as they were sceptical and did not want the 'ugly thing' to mess up the order of the house. As participants discovered benefits from using the computer, it was moved from the hidden place, to a place where it was easier to use. Often it was moved to the most important room.

I5, Man 83 years: I had it in the son's old room earlier. I really never use that part of the house and it turned out to be inconvenient. Then I moved it here, where I spend most of my time. I had to pay for the reinstalling myself, but it was worth it.

\section{Developing social networks}

The second theme was formed by the three subthemes Revitalising of social and supportive connections, Reconnecting with the ill person and Developing relationships with technology and objects. Several participants had for years experienced loneliness and social isolation. The nature of caring had led to difficulties leaving the home and old friends had disappeared over time. After starting with Internet-based caregiver support, the participants had developed new social networks.

\section{Revitalising of social and supportive connections}

At first, the new network was limited to support nurses. Besides providing education, nurses became more accessible than before, thereby playing a new part as advisor in big and small issues. Nurses encouraged participants to contact other members of the online social community, which resulted in participants making new friends among peer caregivers.

I6, Man 75 years: One becomes very isolated in this situation. You loose contact with everything around you. Here in the computer I have a list of persons who knows what it is like, and they want to talk to me. I don't feel so lonely anymore.

All participants had family members living far away. Networking with such family members was extended through online chatting and video communication services. More frequent and more regular contacts were developed, as compared to before they used Internet-based caregiver support. Visual contact made a feeling of actually being together.

I7, Woman 75 years: Being able to look at each other adds another dimension. You can read facial expressions. When you don't meet often it is difficult to know what to talk about on the telephone. Visual contact has given us more to talk about. We talk more often now too.

\section{Reconnecting with the ill person}

For some participants, the relationship with the spouse came to a new start. Participants who found ways to include the spouse in using the computer found it added meaningfulness to their relationship.

I3, Woman 72 years: Thanks to the computer we do things together now. Like we used to do. For many years we haven't done much together. He was sitting in there, and I tended to my duties. When I had time over I spent it alone, not with him.

Developing relationships with technology and objects

It was quite common that participants in the interviews referred to the computer as 'he', giving it status as a subject and thereby referring to the computer as a partner with human qualities. One participant described the computer as a friend.

I8, Man 75 years: Well, he is a friend, I mean the computer, that I can always turn to.

Also the environment in the house, objects and rooms, became part of the extended network. One participant had placed the computer in the large living room which had lost its purpose as drawing-room as he and his wife had stopped having visitors years ago. After having had webcam contacts with other caregivers in the network, he discovered how they often commented on the things he had on the walls, asking questions and using them as ice-breakers. Relationships with artefacts and decorations in the room deepened, as they strengthened the participants' identity in the virtual meetings with others.

I9, Man 83 years: It's amazing how these old things have gained new meaning. Other people find them interesting, want to look at them and we talk about them.

\section{Discussion}

The aim of this study was to explore how Internet-based caregiver support may influence the experience of isolation among older spouse caregivers living in rural areas. Long 
distances prevent the possibility to pop in for coffee with the neighbours or running quick errands to the store, if there are any stores in the area. Many participants in the study had over 40 minutes by car to reach a convenience store, and no neighbours within walking distance. The findings reveal that caregivers' experience of isolation had been changed since they started using the Internet-based caregiver support system. Although they still were physically present in their remote homes, Internet, as well as the Internet-based caregiver support system, presented them to a tool to build up contact with family and develop new friends.

Variations of the concept of place were essential as the spouse caregivers had been able to extend their concept of place and loosen up the boundaries of the home, where they used to, and still spent almost all their time. Daily life was experienced as being spent in a variety of places, both physically, virtually and emotionally. Some of the places were private, others were shared with the spouse or others. Research has shown that the action of moving between points within the house has both physical and psychological benefits (Peace et al., 2005). Our study also highlighted that the caring situation had caused the participants to have feelings of isolation and withdrawal from wider social networks. Using Internet-based caregiver support enabled them to form social networks and break isolation. They found a way for a virtual escape from entrapment in the house (Imrie, 2004). These findings are supported by a recent American study indicating that using the Internet may decrease isolation among older persons (Cotten et al., 2013).

The concept of place has traditionally been defined by its geographical location. Hagberg (2012) describes how the use of new communication technologies has opened up for new and more complex spatial definitions. Where one 'is' becomes an issue of which places one can connect to in real time. From this perspective, an older person who is physically tied to the home can simultaneously live in a home where he or she can visit other places and be a virtual nomad in the world. For older spouse caregivers living in rural areas, it also means that limitations caused by long distances and lack of services in part can be overcome.

As participants experienced benefits from using Internet, the computer made a spatial journey, from a hidden place into a significant place in the home. Participants in the study described how they with time had 'become friends' with the computer and how networks and relationships had improved after they started using Internet-based support. They often referred to their computers as subjects, giving the computer credit for 'doing things' and adding meaning. Besides affecting the relationship with the cared for spouse in a positive manner, relationships with support nurses and family members living far away had undergone further development. In actor network theory, Latour $(1992,2005)$ points out that technological objects act for and with humans, influence humans and as a result also have an impact on the relationship between humans.

The support nurses played a crucial part in the development. Through the Internet-based caregiver support, participants obtained increased access to nurses, who encouraged the participants to explore various ways to use the support service. The nurses educated the caregivers to use the system supporting their independency. Initially, many of the participants were sceptical to receiving Internet-based caregiver support. Over time, their attitudes changed, both towards Internet and using the computer. Interaction with the computer transformed from being strange and artificial into becoming an unconscious, natural act. According to Benner and Wrubel (1989), caring includes relationships between people as well as relationships between people and things, or situations, that human's value. By utilising a person's own resources and helping them to find new ways to cope, they can achieve well-being. Preventing unnecessary deterioration in the health of caregivers is one of the cornerstones of supporting older family caregivers and essential in order to meet future needs of long-term care of older people (European Commission, 2008).

Social infrastructure in rural areas throughout the world is changing, with depopulation and loss of healthcare services and other essential services, leading to older people in rural areas becoming even more vulnerable (Phillipson \& Scharf, 2005). For older spouse caregivers, it may be nearly impossible to get a break (Chappell et al., 2008). With children often living far away and distant neighbours, practical assistance from friends and relatives is usually not readily available. Previous research has shown that older rural caregivers experience more feelings of abandonment from the family and have more difficulties obtaining access to professional care than caregivers in urban areas (Ehrlich et al., 2014).

In this study, it appears that nurses were a prerequisite for spouse caregivers obtaining the feeling that they were given expanded space for living. This meant that caregivers could 'travel' from home, experience other places, resume contacts and make new friends without leaving the house. A recent review of interventions targeting social isolation in older people stated that social activity and support within a group format are common characteristics of effective interventions (Dickens et al., 2011). Thanks to the tangible help from nurses; the older spouse caregivers were able to network with others even without physical in real-life group participation. Another factor with positive influence on the outcome of 
caregiver support aimed at older spouse caregivers is to receive the support for a longer time period (Chien et al., 2011; Kjallman Alm et al., 2013). In our study, caregivers had used the Internet-based support service for 18 months.

Nursing is part of the social structure and nurses constitute the largest group of healthcare workers (The Institute of Medicine, 2010). Society can therefore use this group as a central part of the solution to challenges that originate from an ageing population, increased need for long-term care, rural depopulation and increased need for support to older spouse caregivers in rural areas. What distinguishes the registered nurses' involvement in people's lives from other professional bodies is the direct, intimate continuity of nursing care that related to human needs and critical life situations (Theodoridis, 2013). Although many older spouse caregivers live in rural municipalities which do not make use of Internet-based solutions for providing caregiver support, we would like to suggest an alternative way to put the knowledge generated through this study into practice. Even though older adults use Internet less than other age groups, Internet use among persons 65 years and older is growing (Zickuhr \& Madden, 2012). It might be an idea to stimulate nurses to make a habit of enquiring about caregivers' access to Internet and inspire older spouse caregivers to use existing technology and software that is free of charge. With encouragement from nurses, more caregivers can decrease isolation through developing social networks and experience widening the boundaries of the home.

\section{Methodological considerations}

As this study was performed on data gathered within another study, it was not possible to influence the questions asked during interviews and gather data specifically in accordance with the aim of this study. The purpose of the original study was to explore participants' experiences of receiving Internetbased caregiver support, not to investigate its effect on isolation or loneliness (Blusi et al., 2013). If the focus of the interviews had been directed more towards the aim of this study, it is possible that even more knowledge could have been discovered. Despite this limitation, we apprehend the data at hand represented a theoretical saturation of the topic under study. The number of participants was fairly large for this type of study, which gave trustworthiness and variation of experiences. Achieving trustworthiness, including the aspects of credibility, dependability and transferability, are essential steps in qualitative content analysis (Graneheim \& Lundman, 2004). Through the use of quotations, it is possible to see data, and as shown in Table 1, it is possible to follow an example of the process of analysis. These are essential aspects for judging the credibility of the study (Graneheim \& Lundman, 2004). The trustworthiness also relates to the transferability of the findings (Guba, 1981). It is up to the reader to make a realistic assessment of whether or not the findings can be transferred to other similar contexts.

\section{Acknowledgements}

The authors wish to thank local municipalities and support nurses in Jämtland, Härjedalen, Västerbotten, Lappland, Angermanland and Medelpad, Sweden. We also thank the funding organisations supporting our study: Association of Local Authorities in Västernorrland County, Swedish Institute of Assistive Technology, Västernorrland County Council, Telia and Mid-Sweden University. No conflict of interest has been declared by the authors.

\section{Funding}

Swedish Institute of Assistive Technology, Association of Local Authorities in Västernorrland County, Västernorrland County Council, Telia and Mid-Sweden University.

\section{Implications for practice}

- Internet-based caregiver support seems to reduce feelings of isolation among older family caregivers in rural areas

- Internet enables social activities for caregivers who are unable to physically participate in activities outside the home.

- Nurses play an important role in encouraging caregivers to use Internet and discover new social contexts.

\section{Contributions}

Study design: MB, MJ; data collection: MB; data analysis and manuscript preparation; MB, LK, MJ.

\section{References}

Alzheimer's Association (2011) Alzheimer's disease facts and figures. Alzheimer's and Dementia 7, 24-33 Available at: http:// www.alz.org/downloads/facts_figures_2013.pdf (accessed 03 July 2014).

Benner P. \& Wrubel J. (1989) The Primacy of Caring: Stress and Coping in Health and Illness. Addison-Wesley, Menlo Park.

Berner J., Rennemark M., Jogreus C., Anderberg P., Skoldunger A., Wahlberg M., Elmståhl S. \& Berglund J. (2014) Factors influenc- 
ing Internet usage in older adults (65 years and above) living in rural and urban Sweden. Health Informatics Journal, February 24, 2014, 1-13. Published online before print doi:10.1177/ 1460458214521226.

Blusi M., Asplund K. \& Jong M. (2013) Older family carers in rural areas: experiences from using caregiver support services based on Information and Communication Technology (ICT). European Journal of Ageing 10, 191-199.

Blusi M., Dalin R. \& Jong M. (2014) The benefits of e-health support for older family caregivers in rural areas. Journal of Telemedicine and Telecare 20, 63-69.

Burton A., Kwak J. \& Haley W. (2004) Elder caregiving. In Encyclopedia of Applied Psychology. (Charles S. ed.). Elsevier, New York, pp. 703-711.

Carretero S., Stewart J., Centeno C., Barbabella F., Schmidt A., Lamontagne-Godwin F. \& Lamura G. (2012) Can Technologybased Services support Long-term Care Challenges in Home Care?: In Analysis of evidence from social innovation good practices across the EU CARICT Project Summary Report. Institute for Prospective Technological Studies European Commission Joint Research Centre, Luxembourg.

Chappell N., Schroeder B. \& Gibbens M. (2008) Respite for rural and remote caregivers. In Rural Ageing - A Good Place to Grow Old? (Keating N. ed.). The Policy Press, Bristol, pp. 53-62.

Chien L., Chu H., Guo J., Liao Y., Chang L., Chen C. \& Chou K. (2011) Caregiver support groups in patients with dementia: a meta-analysis. International Journal of Geriatric Psychiatry 26, 1089-1098.

Cockram J., Hancock P. \& Jarvis J. (2007) Supporting older carers of people with a disability: an evaluation of a respite care program in Western Australia. Asia Pacific Journal of Health Management 2, $58-62$.

Cotten S., Anderson W. \& McCullough B. (2013) Impact of internet use on loneliness and contact with others among older adults: cross-sectional analysis. Journal of Medical Internet Research 15, E39.

Dickens A., Richards S., Greaves C. \& Campbell J. (2011) Interventions targeting social isolation in older people: a systematic review. BMC Public Health 11, 647.

Ehrlich K., Boström A., Mazaheri M., Heikkilä K. \& Emami A. (2014) Family caregivers' assessments of caring for a relative with dementia: a comparison of urban and rural areas. International Journal of Older People Nursing [Epub ahead of print] 17 Jan 2014 Doi: 10.1111/opn.12044.

Ekwall A., Sivberg B. \& Hallberg I. (2004) Dimensions of informal care and quality of life among elderly family caregivers. Scandinavian Journal of Caring Sciences 18, 239-248.

European Commission, Employment, Social Affairs and Equal Opportunities DG (2008) Long-term care in the European Union. Available at: http://ec.europa.eu/social/main.jsp?catId=792\&langId=en (accessed 14 May 2014)

Gallagher D., Mhaolain A., Crosby L., Ryan D., Lacey L., Coen R., Walsh C., Coakley D., Walsh J. \& Cunningham C. (2011) Determinants of the desire to institutionalize in Alzheimer's caregivers. American Journal of Alzheimer's Disease and Other Dementias 26, 205-211.
Graneheim U. \& Lundman B. (2004) Qualitative content analysis in nursing research: concepts, procedures and measures to achieve trustworthiness. Nurse Education Today 24, 105-112.

Guba E. (1981) Criteria for assessing the trustworthiness of naturalistic inquiries. Educational Technology Research \& Development. 29, 75-91 ISSN 0148-5806.

Hagberg J. (2012) Older persons' sense of belonging to their place of living. In Housing for Older People - Research Perspectives in the Nordic (Abramsson M. \& Nord C. eds), Studentlitteratur, Lund, pp. 19-33 (In Swedish).

Hoffmann F. \& Rodrigues R. (2010) 'Informal Carers - Who Takes Care of Them?' Policy Brief, April 2010. European Centre for Social Welfare Policy and Research, Vienna.

Imrie R. (2004) Disability, embodiment and the meaning of the home. Housing Studies 19, 745-763.

Johansson L. (2007) Family Carers - Care and Support. Studentlitteratur, Lund (In Swedish).

Keating N. (2008) Rural Ageing. A Good Place to Grow Old? The Policy Press, Bristol.

Kjallman Alm A., Hellzen O. \& Norbergh K. (2013) Experiences of long term ongoing structured support in early stage of dementia-a case study. International Journal of Older People Nursing, doi: 10.1111/opn.12034.

Kröger T. (2003) Families, Work and Social Care in Europe. European Comission, Brussels.

Kvale S. \& Brinkmann S. (2009) Interviews: Learning the Craft of Qualitative Research Interviewing, 2nd edn. Sage Publications, Los Angeles.

Lamura G., Mnich E., Nolan M., Wojszel B., Krevers B., Mestheneos L., Döhner H. \& Groupobot E. (2008) Family Carers' Experiences Using Support Services in Europe: Empirical Evidence From the EUROFAMCARE Study. Gerontologist 48, 752-771.

Larsson K. (2006) Housing in Old Age, Stay Put or Moving Out? - A Systematic Review. Stiftelsen Stockholms läns Äldrecentrum, Stockholm (In Swedish).

Latour B. (1992) Where are the missing masses. Sociology of a door. Available at: http://www.bruno-latour.fr/sites/default/files/50MISSING-MASSES-GB.pdf (accessed 17 January 2014)

Latour B. (2005) Reassembling the Social. An Introduction to ActorNetwork-Theory. Oxford University Press, New York.

Leggett A., Zarit S., Taylor A. \& Galvin J. (2011) Stress and burden among caregivers of patients with Lewy body dementia. Gerontologist 51, 76-85.

Magnusson L., Hanson E. \& Nolan M. (2005) The impact of information and communication technology on family carers of older people and professionals in Sweden. Ageing and Society 25, 693-713.

Marin B., Leichsenring K., Rodrigues R. \& Huber M. (2009) Who Cares? Care Coordination And Cooperation To Enhance Quality In Elderly Care in the European Union In Conference on Healthy and Dignified Ageing. European Centre for Social Welfare Policy and Research, Affiliated to the United Nations, Stockholm.

McConaghy R. \& Caltabiano M. (2005) Caring for a person with dementia: exploring relationships between perceived burden, depression, coping and well-being. Nursing \& Health Sciences 7, 81-91. 
Nicholson N. (2012) A review on social isolation: an important but underassessed condition in older adult. Journal of Primary Prevention 33, 137-152.

NVivo (2012) NVivo qualitative data analysis software; QSR International Pty Ltd. Version 10. 2012. Available at: http://www. qsrinternational.com/products_nvivo.aspx (accessed 18 April 2014).

Patton M. (2004) Qualitative Research \& Evaluation Methods, 4th edn. SAGE, London.

Peace S., Holland C. \& Kellaher L. (2005) Making space for identity. In Ageing and Place. (Andrews G. \& Phillips D. eds). Routledge, Oxon, pp. 188-204.

Phillipson C. \& Scharf T. (2005) Rural and urban perspectives on growing old: developing a new research agenda. European Journal of Ageing 2, 67-75.

Post and Telecom Authorities (2010) Swedes - the swiftest surfers in the Nordic countries. Available at: http://www.pts.se/en-GB/News/ Press-releases/2010/Swedes-the-swiftest-surfers-in-the-Nordiccountries/ (accessed 30 June 2014).

Sand A. (2005) Informal Care Of Older People and Support for Informal Carers - a Scandinavian Research Review. Nordic Council of Ministers, Copenhagen (In Swedish).

Schmidt A., Chiatti C., Fry G., Hanson E., Magnusson L., Socci M., Stückler A., Széman Z., Barbabella F., Hoffmann F. \& Lamura G. (2011) Analysis and Mapping of 52 ICT-Based Initiatives for Caregivers Deliverable 2.3. Vienna, 23rd July 2011. European Centre for Social Welfare Policy and Research, Vienna.
Swedish National Rural Development Agency (2007) Swedish rural areas and definitions (In Swedish). Sveriges gles- och landsbygder 2007. Glesbygdsverket. Available at: http://www. growthanalysis.se/download/18.56ef093c139bf3ef890294d/ 1349863628560/landsbygdsdefinitioner-i-sverige-och-andralander-08.pdf (accessed 04 July 2014).

Swedish Social Services Act (2009) Law 2009: 549. Available at: http:// www.riksdagen.se/sv/DokumentLagar/Lagar/Svenskforfattningssamling/Socialtjanstlag-2001453_sfs-2001-453/?bet=2001:453 (accessed 28 June 2014).

The Institute of Medicine (2010) The Future of Nursing - Leading Change, Advancing Health. The Institute of Medicine, Washington, DC Available at: http://www.iom.edu/Reports/2010/ The-Future-of-Nursing-Leading-Change-Advancing-Health.aspx (accessed 23 June 2014).

Theodoridis K. (2013) Omvårdnad som filosofisk aktivitet -en teoretisk studie. Nordic Journal of Nursing Reseach 108, 11-15.

Winqvist M. (2010) Individualisation, evaluation and development of family support - A systematic review. Kunskapsöversikt 2010:2. Nationellt kompetenscentrum Anhöriga, Kalmar (In Swedish).

Winterton R. \& Warburton J. (2011) Models of care for socially isolated older rural carers: barriers and implications. Rural and Remote Health 11, 1678.

Zickuhr K. \& Madden M. (2012) Older adults and internet use. Pew Internet \& American Life Project. Available at: http://www. pewinternet.org/2012/06/06/older-adults-and-internet-use/ (accessed 12 February 2014). 